Received Date : 09-Jul-2015

Accepted Date : 12-Nov-2015

Article type : Review Article

\title{
Functional gastro-intestinal disorder algorithms focus on early recognition, parental reassurance and nutritional strategies
}

\author{
Yvan Vandenplas ${ }^{1}, \mathrm{PhD}$, Marc Benninga ${ }^{2}, \mathrm{PhD}$, Ilse Broekaert ${ }^{3}, \mathrm{MD}$, \\ Jackie Falconer ${ }^{4}, \mathrm{MD}$, Frederic Gottrand ${ }^{5}, \mathrm{PhD}$, Alfredo Guarino ${ }^{6}, \mathrm{PhD}$, \\ Carlos Lifschitz ${ }^{7}, \mathrm{PhD}$, Paolo Lionetti ${ }^{8}, \mathrm{PhD}$, Rok Orel ${ }^{9}, \mathrm{PhD}$, \\ Alexandra Papadopoulou ${ }^{10}, \mathrm{PHD}$, Carmen Ribes-Koninckx ${ }^{11}, \mathrm{PhD}$, \\ Frank M. Ruemmele ${ }^{12,13}, \mathrm{PhD}$, Silvia Salvatore ${ }^{14}$, Raanan Shamir ${ }^{15}, \mathrm{PhD}$, \\ Michela Schäppi ${ }^{16}, \mathrm{MD}$, Annamaria Staiano ${ }^{6}, \mathrm{PhD}$, Hania Szajewska ${ }^{17}, \mathrm{PhD}$, \\ Nikhil Thapar ${ }^{18}, \mathrm{PhD}$, Michael Wilschanski ${ }^{19}, \mathrm{PhD}$
}

${ }^{1}$ Department of Paediatrics, UZ Brussel, Vrije Universiteit Brussel, Brussels, Belgium

${ }^{2}$ Emma Children's Hospital / AMC, Department of Paediatrics, Amsterdam, The Netherlands

${ }^{3}$ Department of Paediatrics, University Hospital Cologne, Germany

${ }^{4}$ Nutrition and Dietetics Dept, Chelsea and Westminster NHS Healthcare Foundation, London, UK

${ }^{5}$ Department of Paediatrics, Jeanne de Flandre University Hospital, CHRU Lille, Faculty of Medicine, University of Lille, France

${ }^{6}$ Department of Translational Medical Science, Section of Paediatrics, University of Naples Federico II, Naples, Italy

This article has been accepted for publication and undergone full peer review but has not been through the copyediting, typesetting, pagination and proofreading process, which may lead to differences between this version and the Version of Record. Please cite this article as doi: 10.1111/apa.13270

This article is protected by copyright. All rights reserved. 
${ }^{7}$ Department of Pediatrics, Section of Gastroenterology, Hepatology and Transplantation. Hospital Italiano, Buenos Aires, Argentina.

${ }^{8}$ Department of Neuroscience, Pharmacology and Child Health, University of FlorenceMeyer children's Hospital, Florence, Italy

9 Department of Gastroenterology, Hepatology and Nutrition, University Children's Hospital Ljubljana, Slovenia

${ }^{10}$ First Department of Paediatrics, University of Athens, Children's Hospital "Agia Sofia"

11 Paediatric Gastroenterology and Hepatology Unit, La Fe University Hospital, Valencia, Spain

${ }^{12}$ APHP-Hôpital Necker Enfants Malades, Service de Gastroenterologie Pédiatrique, Paris, France

${ }^{13}$ Université Sorbonne Paris Cité - Paris Descartes, Faculté de Médecine, Paris, France

${ }^{14}$ Paediatric Department, University of Insubria, Varese, Italy.

${ }^{15}$ Schneider Children's Medical Centre of Israel, Sackler Faculty of Medicine, Tel-Aviv University, Israel.

${ }^{16}$ Paediatric Center, Clinique des Grangettes and Centre Médical Universitaire, Geneva, Switzerland

${ }^{17}$ Department of Paediatrics, The Medical University of Warsaw, Warsaw, Poland

${ }^{18}$ Gastroenterology Unit, Great Ormond Street Hospital and UCL Institute of Child Health, London, United Kingdom

19 Paediatric Gastroenterology, Hadassah Hebrew University Medical Center, Jerusalem, Israel

Short title: Cows' milk algorithms

Key-words: constipation, colic, cows' milk allergy, functional disorder, regurgitation

This article is protected by copyright. All rights reserved. 
Address for correspondence: Yvan Vandenplas, UZ Brussel, Laarbeeklaan 101, 1090 Brussels, Belgium.

e-mail: yvan.vandenplas@ @uzbrussel.be; Tel + 3224775780; Fax: +3224775783

\section{Conflict of Interest:}

None of the authors have any conflicts of interest relevant to this paper to disclose.

\section{Abstract}

Up to $50 \%$ of infants present with symptoms of regurgitation, infantile colic and, or, constipation during the first 12 months of life. Although they are often classed as functional disorders, there is an overlap with cows' milk allergy. We present practical algorithms for the management of such disorders, based on existing evidence and general consensus, with a particular focus on primary healthcare. Management consists of early recognition of warning signs of organic disease, parental reassurance and nutritional strategies. Conclusion. The proposed algorithms aim to help healthcare providers manage frequent gastrointestinal and cows' milk related symptoms in infants safely and effectively.

\section{Key Notes}

- Up to $50 \%$ of all infants present with symptoms of regurgitation, infantile colic and, or, constipation during the first 12 months of life.

- We present practical algorithms for the management of frequent gastrointestinal and cows' milk related symptoms, based on existing evidence and general consensus, with a particular focus on primary healthcare.

This article is protected by copyright. All rights reserved. 
- The algorithms focus on early recognition of the warning signs of organic disease, parental reassurance and nutritional strategies.

\section{INTRODUCTION}

Although functional gastrointestinal disorders (FGID), such as regurgitation, infantile colic and constipation, are considered to be benign conditions, they occur in up to $50 \%$ of infants and are often frustrating for parents and carers. Each of these FGIDs occurs in $20-25 \%$ of infants, who may present with a combination of symptoms (1). Functional gastrointestinal symptoms are considered to be transient, self-limiting conditions. However, limited data suggest that symptoms such as infantile colic may be associated with recurrent abdominal pain, migraine, allergic disorders, sleep disturbances and maladaptive behaviour, such as aggressiveness, later in life (2).

The Rome III consensus has proposed diagnostic criteria for these symptoms, but not for the management of them (3). Functional gastrointestinal symptoms are not a reason to stop breastfeeding and almost half of all infants who are formula-fed have at least one change of formula because of gastrointestinal symptoms during their first six months of life (4). This reflects the anxiety of parents and the search for a remedy by both the parents and the doctors. The natural course of these symptoms is for them to spontaneously disappear.

Children with cows' milk allergy (CMA) can present with one or more of the above symptoms and the clinical discrimination between FGID and CMA may be challenging (5). Symptoms of CMA are non-specific (5) and it is difficult for primary healthcare providers to diagnose CMA. Therefore, the preferred terminology is cows' milk related symptoms, as this does not differentiate between FGID and CMA as the cause of the symptoms. Because of the longterm impact of a diagnosis of CMA on later health, such as an increased risk for other atopic

This article is protected by copyright. All rights reserved. 
manifestations or diseases (6), this diagnosis should only be made by specialists such as paediatric allergists or appropriately experienced gastroenterologists. Asthma, allergic rhinitis and eczema are more common in children with a history of CMA than would be expected in the general population (6). While the self-reported lifetime prevalence of CMA is $6 \%(5.7-6.4)$, the prevalence of CMA defined by a positive food challenge is only $0.6 \%(0.5-$ 0.8) (7).

This paper gives practical advice that will enable primary healthcare providers to recognise and manage common FGID and cows' milk related symptoms in infants more effectively. Practical recommendations and algorithms have been developed and discussed. These may need to be adapted to account for local circumstances and individual patient situations.

\section{Methods}

The authors did not aim to replace the evidence-based guidelines of the North American Society of Paediatric Gastroenterology, Hepatology and Nutrition Society of Paediatric Gastroenterology, Hepatology and Nutrition (NASPGHAN) or the European Society of Paediatric Gastroenterology, Hepatology and Nutrition (ESPGHAN) on CMA, gastrooesophageal reflux (GOR) or constipation $(5,8,9)$. We searched MEDLINE, Embase, the Cochrane Database of Systematic Reviews, the Cochrane Central Register of Controlled Clinical Trials and PubMed from the end of the literature searches mentioned in the ESPGHAN guidelines on cow's milk allergy (2012) and the NASPGHAN/ESPGHAN guidelines on gastro-oesophageal reflux and constipation (2009 and 2014, respectively) up to October 2014. With regard to infantile colic, the literature was searched for papers not included in three systematic reviews $(10,11,12)$. Our paper provides a follow-up of the consensus algorithms that were developed by Belgian paediatric gastroenterologists (13).

This article is protected by copyright. All rights reserved. 
The authors of this paper, who come from different parts of the world, made recommendations based on the evidence, when it was available, and on the consensus if the evidence was missing. The practical recommendations contained in this paper should be applicable worldwide.

In November 2014 the Gastroenterology Committee of ESPGHAN discussed the contents of this paper in detail and voted on the statements during a face-to-face meeting. This group decided to include additional key opinion leaders, who participated in electronic discussions and voting. Finally, the statements were given to another selected group of experts who only participated in the voting. As a result, 22 key opinion leaders from different regions of the world participated in the voting.

In order to reach a consensus, we used a structured method that had previously been shown to be effective $(9,14)$. Consensus was formally achieved through a nominal group technique, which is a structured quantitative method. The group consisted of 22 members who voted anonymously. Before the voting took place, the statements were reviewed by each co-author until agreement was reached. A nine-point scale was used, ranging from one for strongly disagree to nine for fully agree (15). It was decided beforehand that consensus was deemed to be reached if more than $75 \%$ of the votes were scores of six, seven, eight or nine. A vote of six and above meant agreement, with nine being an expression of stronger agreement than six.

\section{Regurgitation}

Regurgitation, the passage of refluxed gastric contents into the pharynx or mouth, is physiological. Most regurgitation episodes occur during the postprandial period and cause few or no other symptoms (8). The five statements related to regurgitation and the associated voting results are listed in Table 1.

This article is protected by copyright. All rights reserved. 
According to the Rome III criteria, regurgitation in an infant of between three weeks and 12 months of age includes: regurgitation two or more times per day for three weeks or more and an absence of nausea, hematemesis, aspiration, apnoea, failure to thrive, difficulty in feeding or swallowing and abnormal posture (3). More than $50 \%$ of three to four-month-old infants regurgitate daily, fulfilling the Rome III criteria (8). At least two studies have showed that four or more episodes of regurgitation occurred in about $20 \%$ of all infants and that $20 \%$ of mothers sought medical help for this (8). Investigations are not recommended to diagnose regurgitation. Differential diagnoses should be considered in infants who are younger than one week and older than six months, as physiological regurgitation rarely starts before the age of one week or after six months (8).

The management of regurgitation is as follows (Figure S1). In infants with frequent and troublesome regurgitation, a complete medical history and physical examination is warranted to rule out organic disease. As physiological regurgitation should not be diagnosed in an infant with vomiting and poor weight gain, anthropometry is of major importance (8). The management of regurgitation starts with reassuring parents, by providing information on the natural history of regurgitation and correct formula preparation if the infant is not breastfed, together with advice on how overfeeding may exacerbate symptoms (8). Regurgitation is not a reason to stop breastfeeding. The nutritional management of regurgitation consists of correcting the frequency and volume of feeds, if necessary (8). Thickened formula or antiregurgitation formula decreases regurgitation (8). Placing infants in a prone, antiTrendelenburg position cannot be recommended because of the risk of sudden infant death syndrome (SIDS) (8). However, there is limited evidence for some efficacy of an antiregurgitation bed with an angle of $40^{\circ}$ anti-Trendelenburg (16). Putting the infant to sleep on its side has also been recommended, but is associated with an intermediate risk of SIDS, between prone and supine sleeping (17). Proton pump inhibitors do not decrease infant

This article is protected by copyright. All rights reserved. 
regurgitation, crying, distress or irritability (18). There is no indication for drug treatment in 'happy spitters' or in infants with troublesome regurgitation.

Commercial anti-regurgitation formulae contain different thickening agents, such as processed rice, corn or potato starch, guar gum or locust bean gum. If a commercial antiregurgitation formula is not available, a thickening product may be added to standard formula. Cereals increase the infants' caloric intake, possibly inducing excessive weight gain and altering the fat and protein energy ratio. Locust bean gum does not increase the caloric density, but may cause bloating (19). Home thickening of a regular formula increases the osmolarity, which may in itself induce reflux by increasing the number of transient lower oesophageal sphincter relaxations (8). Infants with persistent regurgitation and, or, vomiting should be referred to a paediatric gastroenterologist (8).

A limited number of studies have suggested that specific probiotics, namely Lactobacillus (L.) reuteri DSM 17938, and prebiotics prevent regurgitation $(20,21)$. L. reuteri DSM 17938 accelerates gastric emptying. The gastric emptying of a partial protein hydrolysate is faster than that of intact protein, which may decrease regurgitation (22). CMA should be suspected in an infant with persistent and recurrent regurgitation, especially when it is associated with other manifestations of allergic disease, such as atopic dermatitis and, or, wheezing. These infants should be referred to a paediatric allergist for appropriate diagnosis and management.

\section{Infantile colic}

The historic definition of infantile colic consists of crying lasting three or more hours a day, at least three days a week for at least three weeks (3). The six statements related to infantile colic, and their voting results, are listed in Table 2. In 2006, the Rome III criteria defined

This article is protected by copyright. All rights reserved. 
infantile colic as: "episodes of irritability, fussing or crying that begin and end for no apparent reason and last at least three hours a day, at least three days a week, for at least one week in an apparently healthy infant with a normal clinical examination" (3). According to a thorough analysis of the literature, the median incidence of infantile colic was about $30 \%$ (23) and it was reported to occur as frequently in breast as bottle-fed infants and equally in both sexes.

The cardinal manifestation of infantile colic is excessive, persistent, inconsolable or unsoothable loud crying, especially in the late afternoon. During each episode the child appears irritable, distressed and fussy, flexes the hip joints, becomes red-faced and has episodes of borborygmi. Multiple aetiologies have been proposed. These include altered gastrointestinal function, food intolerance, transient low lactase activity, CMA, GOR or GOR disease, intestinal dysbiosis, parental coping, anxiety, depression, absence of mother-child reciprocity and the risk of child abuse.

The management of infantile colic is as follows (Figure S2). There are no uniform criteria for a specific therapeutic approach. The first recommended step is to look out for potential warning signs that may indicate organic disease. If these are not present, the feeding technique should be evaluated and the carers should be reassured and supported. Parents should be educated to recognise signs of hunger and fatigue and instructed about structure and regularity. General advice emphasising the self-limiting nature of the condition is important.

This article is protected by copyright. All rights reserved. 


\section{Cows' milk elimination and other dietary interventions}

Infantile colic is not a reason to stop breastfeeding. However, in selected infants with excessive irritability and crying it may be recommended that the lactating mother excludes dairy products for two to four weeks and then reintroduces them. In selected formula-fed infants, there is some evidence that an extensively hydrolysed protein formula reduces infantile colic (10). If the diagnosis of CMA cannot be made by a specialist it is preferable to consider infantile colic as a cows' milk related symptom.

With regard to other dietary interventions, soy-based formula is not recommended, although low-quality studies have reported a reduction in crying time (10). Reviews have suggested that partially hydrolysed protein formula could be beneficial if CMA is not a potential cause of infantile colic $(10,24)$. These formulae are often lactose-reduced or lactose-free and contain prebiotics or probiotics, which may have contributed to a reduction in crying time (10). A meta-analysis showed that L. reuteri DSM 17938 reduced infantile colic in exclusively breastfed infants (12), while a study in mainly formula-fed infants did not show this (25). One study also showed a reduction in maternal depression (26). The same probiotic strain was shown to significantly prevent the onset on infantile colic in formula and breastfed infants $(20,28)$.

A Latin-American expert group concluded that there was grade 1a evidence for L. reuteri DSM 17938 in the prevention of infantile colic and grade $1 \mathrm{~b}$ evidence for its treatment, although the mechanism of action that explains the efficacy of this probiotic remains unclear (28). However, these findings should not be extrapolated to other probiotics, as the efficacy was only demonstrated in breastfed infants and there were no data relating to the probiotic being added to infant formula. Therefore, the use of L. reuteri DSM 17938 in IC should be considered, but is not recommended.

This article is protected by copyright. All rights reserved. 
Although the addition of prebiotics and probiotics to infant formula has not been shown to decrease infantile colic, the evidence seems slightly better for beta-palmitate. One doubleblind, placebo-controlled trial, showed a significant decrease in infantile colic within one week of intervention with a partial hydrolysate, with high $\beta$-palmitate and a specific prebiotic mixture of galacto and fructo-oligosaccharides (29). However, one trial was considered insufficient for a recommendation.

Lactase or reduced lactose are other dietary options that have been explored. A limited number of studies have suggested that transient low lactase activity could trigger excessive crying $(10,30)$. Lactose-free or soy-based formulae have not been consistently demonstrated to be beneficial for patients with infantile colic. The selection of patients is likely to be a major bias in these studies. After some initial enthusiasm about the role of lactase treatment, negative results have suggested that lactose plays a minor role in infantile colic (10). Although a UK recommendation suggested a one-week trial of lactase drops in breastfed and formula-fed infants, the evidence for this recommendation was limited (31). A preventative trial with a formula containing a stable lactase as the result of a fermentation process indicated a decreased incidence of infant crying at the age of four weeks (32). There was insufficient evidence to recommend a trial of lactase or reduced lactose formula in every infant presenting with infantile colic, although this was a safe intervention.

\section{Medication}

Proton pump inhibitors have failed to decrease infant distress in infantile colic (18). Anti-acid medications were not indicated in infantile colic when GOR disease was not diagnosed. Cimetropium caused lethargy, motion sickness and somnolence (33). Hypertonic glucose solutions showed varying effects on crying time (35). Fennel extracts and sucrose solutions had some benefit (35). Allopathic drugs were not proved to be effective (simethicone) and

This article is protected by copyright. All rights reserved. 
some of them caused serious adverse reactions (dicyclomine) (36). In a double-blind study, mentha piperita was shown to reduce infantile colic (37). An extract of Matricariae recutita, Foeniculum vulgare and Melissa officinalis improved infantile colic in breastfed infants (38). However, evidence was too limited to recommend the use of any of these herbal medicinal products for infantile colic.

\section{Swaddling and other caregiving interventions}

There was insufficient evidence to systematically recommend swaddling, although the technique was reported to be of some benefit in infants who were less than eight weeks old (39). Studies have evaluated the role of carers' support, counselling therapy, car rides during colic episodes and a reduction in stimulating actions such as changing diapers and chiropractic and spinal massages. Unfortunately, none of these trials were of sufficient methodological quality (10).

\section{Our conclusion about infantile colic}

Infantile colic is a multi-factorial condition and it is unlikely that a single intervention will significantly reduce it in an unselected population. In infants with proven CMA and infantile colic, the correct treatment is extensively hydrolysed formula or,

if that cannot be tolerated, an amino acid-based formula (5). There has been insufficient evidence to enable us to recommend a trial with L. reuteri DSM 17938 or lactase, although neither induced adverse effects.

This article is protected by copyright. All rights reserved. 


\section{Constipation}

Healthcare practitioners must be aware of normal infant defecation patterns in order to adequately educate and advise parents (3). One study showed that infants who had colic symptoms in the first two months had less frequent defecation during the first two years of life (40). The second month of life was unique in the sense that the frequency of stooling decreased to half of the previous month (40). The four statements related to constipation, and their voting results, are listed in Table 3.

Information should be obtained regarding the duration of the condition, the frequency of bowel movements, the consistency, colour and size of the stools, whether defecation is painful and the presence of blood and mucus. This information will help to make the distinction between functional constipation and constipation due to organic disease. The Amsterdam stool scale may be a useful tool (9). According to the Rome III criteria, the definition of functional constipation includes at least two of the following criteria in an apparently healthy infant: i) two or fewer defecations per week; ii) at least one episode per week of incontinence after the acquisition of toileting skills (not relevant in infants); iii) history of excessive stool retention; iv) history of painful or hard bowel movements; v) presence of a large faecal mass in the rectum; vi) history of large-diameter stools that may obstruct the toilet (not relevant in infants) (3).

Crying and straining associated with defecation of soft stools in otherwise healthy infants who are less than six months of age is defined as functional dyschezia, which is a different condition from constipation. Dyschezia resolves with time without the need for any intervention (3).

This article is protected by copyright. All rights reserved. 
Hard stools occur in only $1 \%$ of exclusively breastfed infants compared to $9.2 \%$ of standard formula-fed infants who do not receive prebiotic or probiotic supplements. (9). While breastfed infants generally produce soft stools ranging from one per week up to six or eight per day, extremes of up to 12 times a day or once every three to four weeks have been reported $(3,9)$. Firm or hard stools often occur when breast milk is switched to infant formula or after the introduction of solids. Harder stools are frequent in infants fed with formula containing vegetable oil that is rich in palmitic acid that is found mainly at the stereospecific numbering (Sn) positions Sn-1 and Sn-3. In mother's milk, palmitic acid is mainly in the Sn-2 position (9). The Sn-1 and Sn-3 positions favour the formation of calcium soaps, responsible for the hard stools, whereas the Sn-2 position is not associated with this problem.

The prevalence rate for constipation in the first year of life has been reported to be $2.9 \%$, increasing up to $10.1 \%$ in the second year (9).

Infants under one year of age are referred for suspected functional constipation because of pain, consistency and frequency of stools. Accompanying symptoms may include irritability, decreased appetite and early satiety, which rapidly disappear after passing stools $(3,9)$.

The management of constipation is as follows (Figure S3). A thorough medical history and physical examination are the cornerstones for diagnosing functional constipation. Failure to pass meconium within 24 hours of birth should raise suspicion of Hirschsprung's disease or cystic fibrosis (9). If an organic cause is not suspected, there is no indication for laboratory or radiographic testing (9). The patient should be referred if they are failing to thrive, have intermittent diarrhoea or abdominal distension (9). At some time in the clinical assessment, every infant with functional constipation should have a digital rectal examination (9). The

This article is protected by copyright. All rights reserved. 
anorectal examination should evaluate perianal sensitivity, anal calibre, position and tone and the presence of an anal wink, fissure or prolapse $(3,9)$.

The first step in the management of functional constipation is parental education and reassurance $(3,9)$. If the probability of an organic condition is low, reassurance and close follow-up are sufficient. Dietary changes and corn syrup resolve constipation in $25 \%$ of cases and laxatives work in $92 \%$ (9). In some infants constipation is related to the intake of CMP, although there is no consensus that extensively hydrolysed formula or soy formulae are indicated for all constipated infants (9). In children with food-related chronic constipation, an increase in both rectal mast cell density and spatial interactions between mast cells and nerve fibres correlates with anal motor abnormalities (41).

In infants who are not constipated, using a formula enriched with prebiotics and, or, probiotics increases the frequency of defecation and softens the stools $(42,43)$. An underpowered study performed with a partial hydrolysate, a prebiotic and $\beta$-palmitate, which is palmitic acid enriched at the Sn-2 position, showed a trend for a softer stool consistency (44).

There is no evidence to support the use of mineral water rich in magnesium to prepare infant formula. Some anti-constipation formulae have a high content of magnesium, albeit within the regulatory limits $(9,45)$. L. reuteri DSM 17938 increases stool frequency in normal infants (20), but only one study has shown that L. reuteri DSM 17938 increased bowel movements in constipated infants, without any difference in consistency and crying episodes (46).

This article is protected by copyright. All rights reserved. 
Lactulose is effective, but causes flatulence (9). Both milk of magnesia and polyethylene glycol are efficient and safe for infants and toddlers (47). Polyethylene glycol is registered in most countries from the age of six months, is at least as effective as lactulose and causes fewer side effects (9).

Juices containing sorbitol, such as prune, pear and apple juices, decrease constipation but induce a risk of unbalanced nutrition (9). Glycerine suppositories can be helpful if acute relief from rectal emptying is needed (9). Evidence does not support the use of mineral oil, as this risks lipoid pneumonia due to aspiration, or enemas such as phosphate in young infants (9).

\section{The role of cows' milk related symptoms and CMA}

CMA is significantly less common than the FGIDS discussed above and occurs in only $3-5 \%$ of formula-fed infants and in $0.5 \%$ of breastfed infants $(5,13)$. Three related statements and their voting results are listed in Table 4. CMA often presents with gastrointestinal manifestations such as regurgitation, vomiting and abnormal defecation, although these are rarely the single manifestation. Most infants with CMA present a combination of symptoms involving different organ systems. Symptoms of CMA and FGID overlap and diagnostic tests do not reliably differentiate between both of them. Therefore, if the diagnosis of CMA cannot be confirmed by a specialist,

it is preferable to designate these symptoms as cows' milk related. A decrease of symptoms with an extensively hydrolysed formula should not be considered as proof of CMA, as gastric emptying is enhanced and stools are softer when this is administered (48).

This article is protected by copyright. All rights reserved. 


\section{Classification and clinical features}

According to the definition proposed by the World Allergy Organization, CMA is a hypersensitivity reaction caused by specific immunological mechanisms to one or more of the proteins present in cows' milk (49). IgE-mediated CMA is characterised by an immediate reaction and is often associated with atopic dermatitis, asthma, and, or, allergic rhinitis. Gastrointestinal symptoms such as regurgitation, vomiting, colic and diarrhoea accompany systemic manifestations of the skin such as urticaria and angio-oedema and the respiratory tract such as rhinitis, wheezing and stridor. There are also shock-like symptoms, which occur usually within minutes or up to two hours later $(5,13)$. Mixed immunoglobulin $E(\lg E)$ and non-IgE mediated CMA constitute a group of disorders that are well defined clinically, but their immunological mechanisms are not well understood. Most of the gastrointestinal symptoms are non-IgE mediated, making it difficult to differentiate functional gastrointestinal symptoms from CMA. Children with a positive food challenge often present with one or more FGIDs. Therefore, it is more appropriate for primary healthcare practitioners to consider that these symptoms are related to the ingestion of CMP rather than proof of CMA.

\section{Diagnosis and management of CMA and cow's milk related symptoms}

Eliminating cows' milk and then carrying out an oral challenge is the standard diagnostic test for CMA or for any symptom related to the ingestion of cows' milk protein. Both over-diagnosis and under-diagnosis have an adverse impact on the child's growth (50). Skin prick testing and specific IgE tests indicate sensitisation to cows' milk protein, while negative tests do not exclude CMA $(5,51)$. Total IgE has a poor specificity for the diagnosis of CMA. Specific IgE and the diameter of the skin prick testing provide information on the prognosis: the higher the specific $\lg \mathrm{E}$ and, or, the larger the diameter of the skin reaction, the longer it will take until tolerance to CMP develops (52). Atopy patch testing is not a recommended procedure (5). 
Children with cows' milk related symptoms or CMA should be monitored for the development of tolerance through repeated oral food challenges (5).

Regarding formula replacement, many guidelines have recommended extensively hydrolysed formula as the first option $(5,13,52,53)$. We refer to previously published algorithms (5). According to the World Allergy Organization guidelines, Diagnosis and Rationale for Action against Cows' Milk Allergy recommend extensively hydrolysed formula over soy formula in IgE-mediated CMA, but stress the need for more data, stating: "there is very sparse evidence suggesting a possible benefit from using eHF compared to soy formula" (49). There is limited evidence that the addition of prebiotics or probiotics, namely $L$. rhamnosus GG or Bifidobacteria breve, to an extensively hydrolysed formula offer any additional benefits $(53,54)$. In an open study, it was suggested that L. rhamnosus $G G$ induced more rapid tolerance (53). However, results from an open study provide insufficient evidence for a recommendation.

Soy is the second option, especially if extensively hydrolysed formula is not available, if it is too expensive or if the child refuses to drink it (5). The Agence Française de Sécurité Sanitaire des Aliments underlined the limited knowledge and uncertainties regarding the presence of isoflavones in soy formulae (55). The American Academy of Pediatrics concluded that $10 \%$ to $14 \%$ of infants with CMA would become sensitised to soy and that this happened more frequently in non-IgE mediated CMA (56). According to a recent metaanalysis the prevalence of soy allergy was $0.5 \%$ in the general population, but the prevalence of sensitisation after the use of soy infant formula was $8.7 \%$ (57). The risk of developing sensitisation to soy should be considered according to the cost-efficacy-risk ratio, which differs according to the socio-economic situation. Although soy protein has been used in infant feeding for more than 100 years, its popularity varies substantially in different parts

This article is protected by copyright. All rights reserved. 
of the world (57). Soy based infant formula has a high content of isoflavones, which have been shown to induce oestradiol-like effects in animal models (58).

Extensive hydrolysates from rice protein, which are on the market in a growing number of countries, may gain greater scientific support as the evidence of their efficacy is growing (59) and they are cheaper than extensively hydrolysed formula. However, the level of arsenic content in rice-based infant formula should be declared (60).

Although regurgitation, constipation or infantile colic in infants may be related to the ingestion of CMP, the immune mechanisms involved can rarely be demonstrated. Therefore, these infants should not be considered as suffering from CMA but as infants presenting with cows' milk ingestion related symptoms. It is important that the healthcare practitioner explains this to the parents, as the long-term outcomes of CMA or food-related symptoms differ.

\section{CONCLUSION}

Infants presenting with gastrointestinal problems such as regurgitation, infantile colic and, or, defecation problems often undergo a series of unnecessary investigations and medical treatments. Overall, medication has failed to deliver significant improvements in these conditions. The practical algorithms presented in this paper focus on reassurance, education and dietary intervention and will assist primary healthcare practitioners in the diagnosis and management of functional gastrointestinal manifestations in infants who are less than 12 months old. The diagnosis and management of CMA are challenging because there are no specific symptoms or diagnostic tests available, other than dietary exclusion and oral

This article is protected by copyright. All rights reserved. 
challenges. Our proposed algorithms are based on the evidence, when it was available, and expert consensus when evidence was not available.

\section{Abbreviations:}

CMA, cows' milk allergy; ESPGHAN, European Society of Paediatric Gastroenterology, Hepatology and Nutrition); FGID, functional gastrointestinal disorders; GOR, gastrooesophageal reflux; IgE, immunoglobulin E; NASPGHAN, North American Society of Paediatric Gastroenterology, Hepatology and Nutrition Society of Paediatric Gastroenterology, Hepatology and Nutrition.

\section{Acknowledgment}

Our thanks go to: Prof Hegar Badriul (Department of Child Health, Faculty of Medicine, University of Indonesia, Cipto Mangunkusumo Hospital, Jakarta, Indonesia), Mauro Morais (Gastroenterologia Pediátrica, Universidade Federal de São Paulo, São Paulo, Brazil), M Miqdady (Pediatric Gl, Hepatology and Nutrition, Sheikh Khalifa Medical City, Abu Dhabi, United Arab Emirates), S Osatakul (Department of Pediatrics, Faculty of Medicine, Prince of Songkla University, Songkhla, Thailand) and F Çullu Çokugras (Department of Pediatric Gastroenterology, Hepatology and Nutrition, İstanbul University, Cerrahpaşa Medical Faculty, İstanbul, Turkey).

This article is protected by copyright. All rights reserved. 


\section{References}

1. Iacono G, Merolla R, D'Amico D, Bonci E, Cavataio F, Di Prima L, et al. Paediatric Study Group on Gastrointestinal Symptoms in Infancy. Gastrointestinal symptoms in infancy: a population-based prospective study. Dig Liver Dis 2005; 37: 432-8.

2. Gelfand AA, Goadsby PJ, Allen IE. The relationship between migraine and infant colic: A systematic review and meta-analysis. Cephalalgia 2015; 35: 63-72.

3. Hyman PE, Milla PJ, Benninga MA, Davidson GP, Fleisher DF, Taminiau J. Childhood functional gastrointestinal disorders: neonate/toddler. Gastroenterology 2006; 130: 1519-26.

4. Nevo N, Rubin L, Tamir A, Levine A, Shaoul R. Infant feeding patterns in the first 6 months: an assessment in full-term infants. J Pediatr Gastroenterol Nutr 2007; 45: 234-9.

5. Koletzko S, Niggemann B, Arato A, Dias JA, Heuschkel R, Husby S, et al; European Society of Pediatric Gastroenterology, Hepatology, and Nutrition. Diagnostic approach and management of cow's milk protein allergy in infants and children: a practical guideline of the GI-committee of ESPGHAN. J Pediatr Gastroenterol Nutr 2012; 55: 221-9.

6. Wood RA. The natural history of food allergy. Pediatrics 2003; 111: 1631-7.

7. Nwaru BI, Hickstein L, Panesar SS, Roberts G, Muraro A, Sheikh A; EAACI Food Allergy and Anaphylaxis Guidelines Group. Prevalence of common food allergies in Europe: a systematic review and meta-analysis. Allergy 2014 ;69: 992-1007

8. Vandenplas Y, Rudolph CD, Di Lorenzo C, et al. Pediatric gastroesophageal reflux clinical practice guidelines: joint recommendations of the North American Society for Pediatric Gastroenterology, Hepatology and Nutrition (NASPGHAN) and the European Society for Pediatric Gastroenterology, Hepatology and Nutrition (ESPGHAN). J Pediatr Gastroenterol Nutr 2009; 49: 498-547.

This article is protected by copyright. All rights reserved. 
9. Tabbers MM, DiLorenzo C, Berger MY, Faure C, Langendam MW, Nurko S, et al. Evaluation and treatment of functional constipation in infants and children: evidence-based recommendations from ESPGHAN and NASPGHAN. J Pediatr Gastroenterol Nutr 2014; 8: 265-81.

10. Hall B, Chesters J, Robinson A. Infantile colic: a systematic review of medical and conventional therapies. J Paediatr Child Health. 2012; 48: 128-37.

11. Dobson D, Lucassen PL, Miller JJ, Vlieger AM, Prescott P, Lewith G. Manipulative therapies for infantile colic. Cochrane Database Syst Rev 2012; 12: CD004796.

12. Urbańska M, Szajewska H. The efficacy of Lactobacillus reuteri DSM 17938 in infants and children: a review of the current evidence. Eur J Pediatr 2014; 173: 1327-37.

13. Vandenplas $\mathrm{Y}$, Alarcon P, Alliet P, De Greef E, De Ronne N, Hoffman I, et al. Algorithms for managing infant constipation, colic, regurgitation and cow's milk allergy in formula-fed infants. Acta Paediatr 2015; 104: 449-57.

14. Vandenplas $\mathrm{Y}$, Dupont $\mathrm{C}$, Eigenmann $\mathrm{P}$, Kuitunen $\mathrm{M}$, Ribes-Koninckx $\mathrm{C}$, et al. A workshop report on the development of the Cow's Milk-related Symptom Score awareness tool for young children. Acta Paediatr 2015; 104: 334-9.

15. McMurray AR. Three decision-making aids: brainstorming, nominal group, and Delphi technique. J Nurs Staff Dev 1994; 10: 62-5.

16. Vandenplas Y, De Schepper J, Verheyden S, Devreker T, Franckx J, Peelman M, et al. A preliminary report on the efficacy of the Multicare AR-Bed in 3-week-3-month-old infants on regurgitation, associated symptoms and acid reflux. Arch Dis Child 2010; 95: 26-30.

17. Loots $C$, Smits M, Omari T, Bennink R, Benninga M, van Wijk M. Effect of lateral positioning on gastroesophageal reflux (GER) and underlying mechanisms in GER disease (GERD) patients and healthy controls. Neurogastroenterol Motil 2013 ;25: 222-9, e161-2.

This article is protected by copyright. All rights reserved. 
18. Gieruszczak-Białek D, Konarska,Z, Skórka A, Vandenplas Y, Szajewska.No effect of proton pump inhibitors on crying and irritability in infants: systematic review of randomized controlled trials. J Pediatr 2015; 166: 767-770.e3

19. Meunier L, Garthoff JA, Schaafsma A, Krul L, Schrijver J, van Goudoever JB. Locust bean gum safety in neonates and young infants: an integrated review of the toxicological database and clinical evidence. Regul Toxicol Pharmacol 2014; 70: 155-69.

20. Indrio F, Di Mauro A, Riezzo G, Civardi E, Intini C, Corvaglia L, et al. Prophylactic use of a probiotic in the prevention of colic, regurgitation, and functional constipation: a randomized clinical trial. JAMA Pediatr 2014; 168: 228-33.

21. Savino F, Maccario S, Castagno E, Cresi F, Cavallo F, Dalmasso P, et al. Advances in the management of digestive problems during the first months of life. Acta Paediatr 2005; 94(Suppl449): 120-4.

22. Vandenplas Y, Leluyer B, Cazaubiel M, Housez B, Bocquet A. Double-blind comparative trial with two antiregurgitation formulae. J Pediatr Gastroenterol Nutr 2013; 57: 389-3.

23. Vandenplas $\mathrm{Y}$, Abkari A, Bellaiche M, Benninga M, Chouraqui JP, Çokura F, et al. Prevalence of functional gastrointestinal symptoms in infants and their impact on health outcomes: literature review and opinion of practising clinicians. J Pediatr Gastroenterol Nutr 2015 (in press)

24. Vandenplas Y, Cruchet S, Faure C, Lee H, Di Lorenzo C, Staiano A. When should we use partially hydrolysed formulae for frequent gastro-intestinal symptoms and allergy prevention? Acta Paediatr 2014; 103: 689-95.

This article is protected by copyright. All rights reserved. 
25. Chau K, Lau E, Greenberg S, Jacobson S, Yazdani-Brojeni P, Verma N, et al. Probiotics for infantile colic: a randomized, double-blind, placebo-controlled trial investigating Lactobacillus reuteri DSM 17938. J Pediatr 2015; 166: 74-8.

26. Mi GL, Zhao L, Qiao DD, Kang WQ, Tang MQ, Xu JK. Effectiveness of Lactobacillus reuteri in infantile colic and colicky induced maternal depression: a prospective single blind randomized trial. Antonie Van Leeuwenhoek 2015; 107: 1547-53.

27. Savino F, Ceratto S, Poggi E, Cartosio ME, Cordero di Montezemolo L, Giannattasio A. Preventive effects of oral probiotic on infantile colic: a prospective, randomised, blinded, controlled trial using Lactobacillus reuteri DSM 17938. Benef Microbes 2015; 6: 245-51.

28. Cruchet S, Furnes R, Maruy A, Hebel E, Palacios J, Medina F. The use of probiotics in pediatric gastroenterology: a review of the literature and recommendations by latin-american experts. Paediatr Drugs 2015;17:199-216.

29. Savino F, Palumeri E, Castagno E, Cresi F, Dalmasso P, Cavallo F. Reduction of crying episodes owing to infantile colic: a randomized controlled study on the efficacy of a new infant formula. Eur J Clin Nutr 2006; 60: 1304-10.

30. Kanabar D, Randhawa M, Clayton P. Improvement of symptoms in infant colic following reduction of lactose load with lactase. J Hum Nutr Diet 2001;14:359-63.

31. Infantile Colic, National Institute for Health Care and Excellence, Clinical Knowledge Summaries, http://cks.nice.org.uk/colic-infantile (website only available in UK)

32. Vandenplas $\mathrm{Y}$, Ludwig $\mathrm{T}$, Bouritius $\mathrm{H}$. The combination of scGOS/lcFOS with fermented infant formula reduces the incidence of colic in 4 week old infants. Arch Dis Child 2014; 99:Suppl 2: A91-2.

33. Savino F, Brondello C, Cresi F, Oggero R, Silvestro L. Cimetropium bromide in the treatment of crisis in infantile colic. J Pediatr Gastroenterol Nutr 2002; 34: 417-9.

This article is protected by copyright. All rights reserved. 
34. Akçam M, Yilmaz A. Oral hypertonic glucose solution in the treatment of infantile colic. Pediatr Int 2006; 48: 125-7.

35. Roberts DM, Ostapchuk M, O'Brien JG. Infantile Colic. Am Fam Physician 2004, 70: 735-40.

36. Metcalf TJ, Irons TG, Sher LD, Young PC. Simethicone in the treatment of infant colic: a randomized, placebo-controlled, multicenter trial. Pediatrics 1994; 94: 29-34.

37. Alves JG, de Brito Rde C, Cavalcanti TS. Effectiveness of Mentha piperita in the Treatment of infantile colic: a crossover study. Evid Based Complement Alternat Med 2012; 2012: 981352.

38. Savino F, Cresi F, Castagno E, Silvestro L, Oggero R. A randomized double-blind placebo-controlled trial of a standardized extract of Matricariae recutita, Foeniculum vulgare and Melissa officinalis (ColiMil) in the treatment of breastfed colicky infants. Phytother Res 2005; 19:335-40.

39. Blom MA, van Sleuwen BE, de Vries $\mathrm{H}$. Health care interventions for excessive crying in infants: regularity with and without swaddling. J Child Health Care 2009; 13: 161-76.

40. Tunc VT, Camurdan AD, Ilhan MN, Sahin F, Beyazova U. Factors associated with defecation patterns in 0-24-month-old children. Eur J Pediatr 2008; 167: 1357-62.

41. Borrelli O, Barbara G, Di Nardo G, Cremon C, Lucarelli S, Frediani T, et al. Neuroimmune interaction and anorectal motility in children with food allergy-related chronic constipation. Am J Gastroenterol 2009; 104: 454-63.

42. Vlieger AM, Robroch A, van Buuren S, Kiers J, Rijkers G, Benninga MA, te Biesebeke R. Tolerance and safety of Lactobacillus paracasei ssp. paracasei in combination with Bifidobacterium animalis ssp. lactis in a prebiotic-containing infant formula: a randomised controlled trial. Br J Nutr 2009; 102: 869-75.

This article is protected by copyright. All rights reserved. 
43. Moro G, Mosca F, Miniello V, Fanaro S, Jelinek J, Stahl B, Boehm G. Effects of a new mixture of prebiotics on faecal flora and stools in term infants. Acta Paediatr 2003; 91 (Suppl 441): 77-9.

44. Bongers ME, de Lorijn F, Reitsma JB, Groeneweg M, Taminiau JA, Benninga MA. The clinical effect of a new infant formula in term infants with constipation: a double-blind, randomized cross-over trial. Nutr J 2007; 6: 8.

45. Chao HC, Vandenplas Y. Therapeutic effect of Novalac-IT in infants with constipation. Nutrition 2007; 23: 469-73.

46. Coccorullo P, Strisciuglio C, Martinelli M, Miele E, Greco L, Staiano A. Lactobacillus reuteri (DSM 17938) in infants with functional chronic constipation: a double-blind, randomized, placebo-controlled study. J Pediatr 2010 ;157: 598-602.

47. Loening-Baucke V. Prevalence, symptoms and outcome of constipation in infants and toddlers. J Pediatr 2005; 146: 359-63.

48. Vandenplas Y, Gottrand F, Veereman-Wauters G, De Greef E, Devreker T, Hauser B. Gastrointestinal manifestations of cow's milk protein allergy and gastrointestinal motility. Acta Paediatr 2012; 101: 1105-9.

49. Johansson SG, Bieber T, Dahl R, Friedmann PS, Lanier BQ, Lockey RF, et al. Revised nomenclature for allergy for global use: Report of the Nomenclature Review Committee of the World Allergy Organization, October 2003. J Allergy Clin Immunol 2004; 113 :832-6.

50. Boyce JA, Assa'ad A, Burks AW, Jones SM, Sampson HA, Wood RA, et al. NIAIDSponsored Expert Panel. Guidelines for the diagnosis and management of food allergy in the United States: report of the NIAID-sponsored expert panel. J Allergy Clin Immunol 2010; 126: $1105-18$.

This article is protected by copyright. All rights reserved. 
51. Skripak JM, Matsui EC, Mudd K, Wood RA. The natural history of IgE-mediated cow's milk allergy. J Allergy Clin Immunol 2007; 120: 1172-7.

52. Fiocchi A, Schünemann HJ, Brozek J, Restani P, Beyer K, Troncone R, et al. Diagnosis and rationale for action against cow's milk allergy (DRACMA): a summary report. $J$ Allergy Clin Immunol 2010; 126: 1119-28.

53. Berni Canani R, Nocerino R, Terrin G, Frediani T, Lucarelli S, Cosenza L, et al. Formula selection for management of children with cow's milk allergy influences the rate of acquisition of tolerance: a prospective multicenter study. J Pediatr 2013 ;163: 771-7.e1.

54. Vandenplas Y, Steenhout P, Planoudis Y, Grathwohl D; Althera Study Group. Treating cow's milk protein allergy: a double-blind randomized trial comparing two extensively hydrolysed formulas with probiotics. Acta Paediatr 2013;102: 990-8.

55. www.afssa.fr; Mars 2005

56. Bhatia J, Greer F, American Academy of Pediatrics Committee on Nutrition. Use of soy protein-based formulas in infant feeding. Pediatrics 2008;121:1062-8.

57. Katz Y, Gutierrez-Castrellon P, González MG, Rivas R, Lee BW, Alarcon P. A comprehensive review of sensitization and allergy to soy-based products. Clin Rev Allergy Immunol 2014; 46: 272-81.

58. Vandenplas Y, Castrellon PG, Rivas R, Gutiérrez CJ, Garcia LD, Jimenez JE. Safety of soya-based infant formulas in children. Br J Nutr 2014; 111: 1340-60.

59. Vandenplas Y, De Greef E, Hauser B; Paradice Study Group. Safety and tolerance of a new extensively hydrolyzed rice protein-based formula in the management of infants with cow's milk protein allergy. Eur J Pediatr 2014; 173: 1209-16.

This article is protected by copyright. All rights reserved. 
60. Hojsak I, Braegger C, Bronsky J, Campoy C, Colomb V, Decsi T, et al; ESPGHAN Committee on Nutrition: Arsenic in Rice - A Cause for Concern. A Comment by the ESPGHAN Committee on Nutrition. J Pediatr Gastroenterol Nutr 2015; $60: 142-5$

Table 1. Statements and voting results on regurgitation

\begin{tabular}{|c|c|c|c|}
\hline Stat & & Consensus & Mean \\
\hline 1 & $\begin{array}{l}\text { Otherwise healthy infants, who present with four or more } \\
\text { episodes of regurgitation per day during at least two } \\
\text { weeks, and in whom the onset is either after the age of } \\
\text { one week or before the age of six months, should be } \\
\text { considered as presenting with physiologic regurgitation } \\
\text { and should be managed by parental reassurance. ( } \geq 4 \\
\text { episodes/d, }>2 \text { weeks duration; onset }>1 \text { week and }<6 \\
\text { months of age). }\end{array}$ & $\begin{array}{l}\text { Yes (19/22) } \\
\text { Agree: } 86 \%\end{array}$ & 7.36 \\
\hline 2 & $\begin{array}{l}\text { Diagnostic investigations are not indicated for the } \\
\text { diagnosis and management of "troublesome } \\
\text { regurgitation". }\end{array}$ & $\begin{array}{l}\text { Yes }(20 / 22) \\
\text { Agree: } 91 \%\end{array}$ & 7.36 \\
\hline 3 & $\begin{array}{l}\text { Anti-regurgitation formula may be considered in infants } \\
\text { with physiologic regurgitation. }\end{array}$ & $\begin{array}{l}\text { Yes }(20 / 22) \\
\text { Agree: } 91 \%\end{array}$ & 7.41 \\
\hline 4 & $\begin{array}{l}\text { Drug treatment is not indicated in the management of } \\
\text { physiologic regurgitation. }\end{array}$ & $\begin{array}{l}\text { Yes }(22 / 22) \\
\text { Agree } 100 \%\end{array}$ & 8.68 \\
\hline 5 & $\begin{array}{l}\text { Drug treatment is not indicated in the management of } \\
\text { physiologic and troublesome regurgitation. }\end{array}$ & $\begin{array}{l}\text { Yes }(17 / 22) \\
\text { Agree } 77 \%\end{array}$ & 7.18 \\
\hline
\end{tabular}

This article is protected by copyright. All rights reserved. 
Legend: Stat: statement

Table 2. Statements and voting results on infantile colic

\begin{tabular}{|c|c|c|c|}
\hline Stat & & Consensus & Mean \\
\hline 6 & $\begin{array}{l}\text { Evidence suggests that the use of extensively } \\
\text { hydrolysed infant formula for a formula fed baby and a } \\
\text { cows' milk free diet for a breastfeeding mother may be } \\
\text { beneficial to decrease infantile colic. However, these } \\
\text { data reflects selected infant populations. }\end{array}$ & $\begin{array}{l}\text { Yes }(21 / 22) \\
\text { Agree } 95 \%\end{array}$ & 7.73 \\
\hline 7 & $\begin{array}{l}\text { There is convincing data that L. reuteri DSM } 17938 \\
\text { decreases infantile colic in well selected breastfed } \\
\text { infants. }\end{array}$ & $\begin{array}{l}\text { Yes (19/22) } \\
\text { Agree } 86 \%\end{array}$ & 7.54 \\
\hline 8 & $\begin{array}{l}\text { However, there is insufficient data to recommend } L \text {. } \\
\text { reuteri DSM } 17938 \text { in all colicky infants. }\end{array}$ & $\begin{array}{l}\text { Yes }(21 / 22) \\
\text { Agree } 95 \%\end{array}$ & 8.32 \\
\hline 9 & $\begin{array}{l}\text { Anti-acid medications are not indicated for colicky infants } \\
\text { without manifestations of gastro-esophageal reflux } \\
\text { disease. }\end{array}$ & $\begin{array}{l}\text { Yes }(22 / 22) \\
\text { Agree } 100 \%\end{array}$ & 8.73 \\
\hline 10 & $\begin{array}{l}\text { There is limited data reporting positive effects of herbal } \\
\text { medicine, such as fennel and peppermint for treatment } \\
\text { of colicky infants. }\end{array}$ & $\begin{array}{l}\text { No (15/22) } \\
\text { Agree } 68 \%\end{array}$ & 6.54 \\
\hline 11 & $\begin{array}{l}\text { However, the evidence of benefit is too limited to } \\
\text { recommend herbal medicine such as fennel and } \\
\text { peppermint for alleviating infantile colic. }\end{array}$ & $\begin{array}{l}\text { Yes }(22 / 22) \\
\text { Agree } 100 \%\end{array}$ & 8.36 \\
\hline
\end{tabular}

This article is protected by copyright. All rights reserved. 
Legend: Stat: statement; italic: statements on which consensus was not reached

Table 3. Statements and voting results on infant constipation

\begin{tabular}{|l|l|l|l|}
\hline Stat & \multicolumn{1}{|c|}{ Mean } & Consensus & Agree 95\% \\
\hline 12 & $\begin{array}{l}\text { Lactulose may be considered as an intervention for } \\
\text { functional constipation. }\end{array}$ & Yes (21/22) & 8.09 \\
\hline 13 & $\begin{array}{l}\text { Macrogol (polyethylene glycol, PEG) may be considered } \\
\text { as an intervention for functional constipation for infants } \\
\text { over six months of age. }\end{array}$ & Agree 95\% & 8.36 \\
\hline 14 & $\begin{array}{l}\text { An extensively hydrolysed infant formula may be } \\
\text { considered as an intervention for functional constipation } \\
\text { for two to four weeks, followed by a challenge with } \\
\text { standard cows' milk infant formula in formula fed infants. }\end{array}$ & Agree 73\% & 6.27 \\
\hline 15 & $\begin{array}{l}\text { Rectal treatment with glycerine suppository should be } \\
\text { restricted to providing acute relief in functional } \\
\text { constipation. }\end{array}$ & Yes (20/22) & 7.82 \\
\hline
\end{tabular}

Legend: Stat: statement; italic: statements on which consensus was not reached

This article is protected by copyright. All rights reserved. 
Table 4. Statements and voting results on CMA

\begin{tabular}{|l|l|l|l|}
\hline Stat & & Consensus & Mean \\
\hline 16 & $\begin{array}{l}\text { The first treatment choice of CMA in formula fed infants } \\
\text { is an extensive cows' milk based hydrolysate. }\end{array}$ & Yes (22/22) & 8.64 \\
\hline 17 & $\begin{array}{l}\text { If extensive cow's milk based hydrolysates are not } \\
\text { available, too expensive or not accepted or tolerated } \\
\text { because of the taste, extensive rice hydrolysates and, } \\
\text { or, soy infant formulae are a valid second choice. }\end{array}$ & Agree 91\% & 7.91 \\
\hline 18 & $\begin{array}{l}\text { There is insufficient data to state that soy based infant } \\
\text { formula would be more unsafe for infants younger than } \\
\text { six months than for older infants. }\end{array}$ & Agree 91\% & 7.36 \\
\hline
\end{tabular}

Legend: Stat: statement

This article is protected by copyright. All rights reserved. 